\title{
Exploring If an Embedded Study-away Experience Impacts Change in Undergraduate Students' Intercultural Competence and Awareness
}

\author{
Kathleen Garrett Rust
}

Elmhurst College, Elmhurst, USA

\begin{abstract}
This research considers the value of an embedded intercultural experience and if it is critical to the development of intercultural knowledge and awareness. Undergraduate students' obtainment of intercultural knowledge and awareness were tested under three conditions: (1) students in a course intentionally designed to develop intercultural self-awareness and intercultural related critical thinking skills (no travel component); (2) students in a course intentionally designed to develop intercultural self-awareness and intercultural related critical thinking skills (including an embedded one-week travel component); and (3) students in a course not specifically designed to develop intercultural self-awareness and intercultural related critical thinking skills (including an embedded one-week travel component). The initial findings suggest that, on average, students who enrolled in courses with the intention of building intercultural competence experienced a positive change in intercultural learning, while students in the course not specifically designed to develop intercultural learning, on average, experienced no change in intercultural learning as measured by the intercultural development inventory (IDI). The results support other findings indicating that immersion in another culture only may not create an opportunity for intercultural learning. This finding reinforces the need for intentional learning opportunities before, during, and after a study-away immersion. However, the omission of an embedded experiential learning opportunity may not lessen intercultural learning.
\end{abstract}

Keywords: cultural development, study-abroad, intercultural competence

\section{Introduction}

Rust and Morris (2013) found very few (if any) studies considering undergraduate students' obtainment of intercultural knowledge, skills, and awareness. This study explores change in intercultural awareness under three conditions: (1) students in a course intentionally designed to develop intercultural self-awareness and intercultural related critical thinking skills (no travel component); (2) students in a course intentionally designed to develop intercultural self-awareness and intercultural related critical thinking skills (including an embedded one-week travel component); and (3) students in a course not specifically designed to develop intercultural self-awareness and intercultural related critical thinking skills (including an embedded one-week

Kathleen Garrett Rust, Ph.D. in business administration, associate professor of business, Elmhurst College, Elmhurst, USA.

Correspondence concerning this article should be addressed to Kathleen Garrett Rust, 190 Prospect Ave., Elmhurst College, Elmhurst, Illinois 60126, USA. E-mail: kathyrst@elmhurst.edu. 
travel component). Students' in this study administered the intercultural developmental inventory (IDI) prior to their study-away experience or at the beginning of the intercultural course. Twelve students participated in the classroom only, while six students participated in each of the courses with a one-week embedded study-away experience. The IDI was administered again, once the students returned to compare their pre study-away and post study-away scores. It was administered to students who did not study away at the end of the course.

\section{Literature Review}

In this study, intercultural competence is defined as students' ability to adapt to cultural differences while abroad and to generalize those skills after they have returned home (Rust \& Morris, 2013; Rust, Forster, Niziolek, \& Morris, 2013; Sample, 2013). This study considers intercultural knowledge and awareness from a developmental perspective that emphasizes the importance of recognizing that intercultural knowledge and awareness increase as one is exposed to numerous competency-building experiences. This process has been described in Bennett's model (1986) of intercultural sensitivity, as one's experience of cultural difference becomes more complex and sophisticated, one's potential knowledge and sensitivity in intercultural relations increase (Hammer, Bennett, \& Wiseman, 2003; Deardorff, 2009). As one continues to experience cultural differences, a greater potential to develop intercultural competence exists.

One way students can experience these cultural differences is through participation in a study-abroad program. Study-abroad programs can take many forms, lasting from few days to a full year (Rust \& Morris, 2013; Rust et al., 2013). They may be in fairly contained programs in which they and other students from a home institution stay together and have faculty from their home institutions; or they may directly enroll in a host institution and live with a family of that culture for the duration of their time abroad. Designed to immerse students in another culture, some of the potential benefits include increased knowledge and understanding of a culture outside of one's own.

A number of studies, using a range of different measures, have attempted to discern what the impact of study-abroad is on the ability of students to sense and adapt to cultural difference. Many have found changes in students' overall awareness to cultural difference, though the results have not been entirely consistent.

Some studies found that short-term programs (fewer than 15 weeks in duration) can still make an impact in intercultural development. Anderson, Lawton, Rexeisen, and Hubbard (2006) examined the effects of a short-term study-abroad program on intercultural sensitivity and awareness and students' response to cultural difference. Results indicate that the study-abroad program had a positive impact on the overall development of intercultural knowledge and awareness.

Jackson (2009) examined advanced second language students from Hong Kong who took part in short-term programs, lasting three to seven weeks after 14 weeks of on campus preparation. While abroad, they lived with a host family, took literary/cultural studies courses, visited cultural sites, participated in debriefing sessions, and conducted ethnographic projects. As a group, the students experienced a significant average gain in intercultural knowledge and awareness. Therefore, even those who have a short-term experience can still improve intercultural knowledge and awareness.

Pederson (2009) examined the impact of curriculum and instruction on intercultural competency. Detailing a year-long study-abroad program, three different conditions existed: (1) students who received an intercultural intervention consisting of a perceptual shift activity and a "meaning-making" exercise facilitated by guided reflection, (2) students who did not receive the intervention, and (3) control students who studied at home. 
Results indicate that those students who received an intercultural pedagogy intervention experienced a statistically significant change in intercultural knowledge and awareness. Similarly, Sample (2013) assessed the development of intercultural competence among a group of students who underwent an interdisciplinary approach to intercultural development to prepare for a semester-long study-abroad experience. Students in the program were required to have at least four semesters of a modern language other than English, and courses in economics, political science, and anthropology prior to their study aboard experience. The results indicated that this approach, which was designed to help students adapt to cultural changes before studying abroad and after they arrive back home, significantly increased their intercultural competence as measured by the change in their pre and post IDI mean change scores. The mean change score was 19.78 points. The difference between their IDI scores in the first semester and after they have studied abroad was statistically significant at the 0.000 level.

In a recent study, Rust and Morris (2013) examined whether 20 undergraduate business students who participated in a four week study-abroad and intercultural competency building coursework would demonstrate a greater increase in intercultural competence over those who enrolled in the study-abroad course only. An IDI was administered to each participant before and after the study-away experience. The results showed that intercultural coursework prior to this study-away experience can have a positive impact on individual intercultural development.

However, some students interested in developing intercultural knowledge may not have the means or access to a substantial study-away experience. Soria and Troisi (2014) looked at alternatives to study abroad, such as intercultural studies courses, lectures, and conferences. They found that these activities increased global, international, and intercultural (known as GII) competencies as efficiently or possibly even more efficiently than study abroad itself.

Vande Berg (2009) summarized the major conclusions of a four-year study designed to measure the intercultural and second language learning of over 1,300 U.S. undergraduates enrolled in over 60 programs abroad. Specifically, the article attempted to answer the question of whether students learn more effectively, when "left to their own devices" (Vande Berg, 2009, p. 15) or whether students learn more, when educators intervene. Results indicate the latter-when students are enrolled in programs with features that are strongly associated with student intercultural learning during their study-abroad stay, they experience greater gains in intercultural development, as measured by the IDI. Students who were merely exposed to a different culture did not have sufficient directed learning opportunities to advance their intercultural learning (Vande Berg, 2009).

These studies all utilized a model of intercultural sensitivity developed by Bennett (1993) and further developed by Hammer $(2009,2011)$. In addition, the IDI was used to measure the change in the participants' intercultural development given the intercultural intervention (i.e., study abroad, intercultural course work, and etc.). This research uses a similar methodology.

\section{Developmental Model of Intercultural Sensitivity}

The developmental model of intercultural sensitivity (DMIS) (Bennett, 1993; Paige, Cohen, \& Shively, 2004; Hammer, 2009, 2011) provides a theoretical framework for explaining the reactions of people to cultural difference. The underlying assumption of the model is that as one's experience of cultural differences becomes more complex, one's potential competence in interactions increases (Hammer \& Bennett, 2001). The modified model (Hammer, 2009) divides the experience of cultural difference into monocultural (denial, polarization, defense, and reversal), transitional (minimization), and intercultural (acceptance and adaptation) mindsets. 
Students with a monocultural mindset assume that their own culture is central to reality. It doesn't occur to them that other people may have different cultural frameworks. If those frameworks are recognized, they will typically judge them in light of their own limited understanding of appropriate human interaction.

\begin{tabular}{|c|c|c|c|c|}
\hline Denial & $\begin{array}{c}\text { Polarization/ } \\
\text { Defense/ } \\
\text { Reversal }\end{array}$ & Minimization & Acceptance & Adaptation \\
\hline & ral Mindset & Transitional & \multicolumn{2}{|c|}{ Intercultural Mindset } \\
\hline
\end{tabular}

Figure 1. The intercultural development continuum.

The continuum represents a progression from a less complex perception of patterns of cultural difference to a more complex experience and understanding of cultural diversity (Hammer, 2009). In denial, people are simply unaware of cultural differences. This may be the result of isolation, occurring naturally or through deliberate avoidance of difference (Bennett, 1993). People in polarization have recognized that there are cultural differences, but other cultures are seen in fairly simple ways and not as complex as their own culture. Students in this stage of development typically rely on stereotypical interpretations of members of other cultures. People in this stage often sense the need to uphold a hierarchy of cultures as a way of making sense of the perceived cultural difference.

In defense, recognition of difference is accompanied by fear and a sense that one's own culture is threatened. From this hierarchical perspective, one's own culture is defined as right, good, and proper, and others are viewed as wrong, bad, and inappropriate. The flip side of defense is reversal; however, people in reversal have reversed the hierarchy by defining their own culture as wrong, bad, and inappropriate, and some other culture with which they are familiar as more desirable. Reversal is often believed by the people experiencing it to be quite sophisticated, because of its critical gaze on the home culture, but in truth, it fails to move beyond the simplistic polarized understanding of cultures and cultural differences (Sample, 2013). The transitional worldview of minimization is neither fully monocultural nor fully intercultural in orientation. Students who subscribe to a minimization orientation are generally able to focus on common cultural artifacts (e.g., love of family), but are less effective at understanding important cultural differences (e.g., how love of family manifests itself) (Sample, 2013). Cultural differences are recognized, but deemed as simply "surface" differences that do not interfere with a real understanding of human relations. Instead, those who minimize cultural difference argue that to really understand people, it is necessary to focus almost exclusively on similarities across cultures.

People with a minimization orientation may consider surface cultural differences interesting or even fun (particularly objective culture, visible aspects like food, art, music, and etc.), but not relevant to truly understand other people. They may well view too much consideration of culture difference to be dangerous. They are likely to think that deep down, everyone is pretty much like them, thus still seeing their own cultural framework as real and natural, and not recognizing the complexity and legitimacy of other cultures (Bennett, 1993; Sample, 2013). 
Students, who move beyond the minimization stage of cultural differences to an acceptance of cultural difference, have moved to an intercultural mindset. This represents a fundamental shift in worldview. In these stages, people understand that their own culture is one of many equally complex ways of organizing human behavior. They are tolerant and are comfortable knowing that there is no "right" answer and that beliefs and practices need to be evaluated within a given cultural context. Acceptance does not mean that one has to agree with or take on a cultural perspective other than one' own. People in this stage accept the viability of different ways of thinking and behaving (Bennett, 1993). Beyond acceptance is adaptation to cultural difference. Adaptation is the ability to see the world through the cultural framework of another or other cultures with which the person is familiar and the ability to (increasingly unconsciously) shift into a different cultural frame of reference. They can empathize with the other cultural perspective in order to understand and be understood by members of other cultures (Bennett, 1993).

\section{Purpose}

The purpose of this research is to consider the value of an embedded intercultural experience. Is it critical to the development of intercultural knowledge and awareness? This study examines whether a week-long embedded study-away experience can increase intercultural knowledge and awareness (with and without an emphasis on intercultural development) and whether students who participated in an intercultural course only can experience an increase in intercultural knowledge and awareness. The change in intercultural knowledge and awareness is determined by comparing the pre and post individual profile score of each participant.

As discussed above, prior research has found evidence that study-abroad experiences do provide opportunities for students to develop intercultural knowledge and awareness (Anderson et al., 2006). Other studies measured intercultural change in students participating in a study-abroad experience and intercultural coursework (Jackson, 2009; Paige et al., 2004; Pederson, 2009; Rust \& Morris, 2013; Sample, 2013). This study examines intercultural development in students under three conditions: (1) students in a course intentionally designed to develop intercultural self-awareness and intercultural related critical thinking skills (no travel component); (2) students in a course intentionally designed to develop intercultural self-awareness and intercultural related critical thinking skills (including an embedded one-week travel component); and (3) students in a course not specifically designed to develop intercultural self-awareness and intercultural related critical thinking skills (including an embedded one-week travel component).

\section{Intercultural Courses}

In this study, students participated under one of three conditions: (A) a 16-week on campus only course without a one-week embedded experience, but designed to develop students' intercultural competence; (B) a 16-week on campus course with a one-week embedded study-away experience not designed to develop students' intercultural; and (C) a 16-week on campus course with a one-week embedded study-away experience designed to develop students' intercultural competence. The IDI was used as the primary measure of intercultural development, similar to its use in the studies described earlier. This instrument was selected, because of its theoretical grounding in Bennett's DMIS and its demonstrated validity and reliability (Hammer et al., 2003; Hammer, 2011).

The 12 students who participated under condition A were enrolled in a course focusing on the people and culture of Hawaii offered through the Department of Intercultural Studies. The course was designed to follow 
Bennett's approach to intercultural development. Students not only learned about the history, cultural, and people of Hawaii, they also participated in assignments designed to learn about perceptions, assumptions, prejudices, and stereotypes, and how these may impact one's interpretation of historical events. Students were asked to analyze their own cultural background and how group affinity may impact the way they view themselves and others. Students were assigned readings that provided interpretations of events in Hawaii from a white male historian's perceptions and that of a native Hawaiian female professor of Hawaiian studies. These students did not travel to Hawaii, but they researched the state and created Hawaiian cultural artifacts, such as flower leis and an in class luau.

Given the findings of other studies, three hypotheses are proposed.

Hypothesis 1: On average, students who participated in the course without a one-week embedded study-away experience, but were intentionally designed to develop intercultural knowledge and awareness, will demonstrate a positive change score in their individual profiles as measured by the IDI.

If the findings are significant, hypothesis 1 would support the research finding that a study-away (abroad) experience may not be critical to intercultural development in undergraduate students (Soria \&Troisi, 2014; Vande Berg, 2009).

The six students who participated under condition B were enrolled in a course focusing on ancient and modern day Olympics. The course was offered through the Department of Kinesiology. Students learned about the importance of play and the historical importance of the Olympic games. Students were required to complete an assignment describing themselves culturally as part of their preparation to study away in Greece one week in the middle of the 16-week term, known as Spring Break. This was the only assignment focused on intercultural development. Students were also required to complete the college's pre-departure requirements of obtaining a valid passport, knowledge of currency, transportation, personal safety, and etc.. Given the lack of intentional assignments designed to increase intercultural knowledge and awareness, hypothesis 2 is proposed.

Hypothesis 2: On average, students who participated in the course with a one-week embedded study-away experience, not intentionally designed to develop intercultural knowledge and awareness, will demonstrate a positive change score in their individual profiles as measured by the IDI after studying abroad.

If the findings are not significant, hypothesis 2 would counter research findings that suggest simple immersion in another culture does not result in a positive change in intercultural development (Vande Berg, 2009).

The six students who participated under condition $\mathrm{C}$ were enrolled in a course focusing on the people and culture of Hawaii that included an offered through the Department of Intercultural Studies. The course was designed to follow Bennett's approach to intercultural development. Students not only learned about the history, cultural, and people of Hawaii, they also participated in assignments designed to learn about perceptions, assumptions, prejudices, and stereotypes, and how these may impact one's interpretation of historical events. Students were asked to analyze their own cultural background and how group affinity may impact the way they view themselves and others. Students were assigned readings that provided interpretations of events in Hawaii from a white male historian's perceptions and that of a native Hawaiian female professor of Hawaiian studies.

This course differed from the course in condition A, since it included a study-away experience on the Island of Oahu, Hawaii for one week in the middle of the 16-week term, known as Spring Break. Students stayed in the resident halls at the university and attended daily lectures provided by professors of Hawaiian and Asian studies. Students also learned the hula from a native dance instructor and the rudiments of the Hawaiian language 
from another university professor. In addition, students visited many important historical sites and museums. Students were also required to complete the home institution's pre-departure requirements of obtaining a valid passport, knowledge of currency, transportation, personal safety, and etc..

Hypothesis 3: On average, students who participated in the course with a one-week embedded study-away experience, intentionally designed to develop intercultural knowledge and awareness, will demonstrate a positive change score in their individual profiles as measured by the IDI after studying abroad.

If the findings are significant, hypothesis 3 would support research findings that suggest students enrolled in courses intentionally designed to enhance intercultural learning before, during, and after their study-abroad stay will experience greater gains in intercultural development, as measured by the IDI (Vande Berg, 2009).

\section{Method}

The study sample consisted of students from a small (3,500 students) liberal arts institution located in the Midwestern United States who participated in one of three courses. In two of the courses, the course topic and teaching approach used was to intentionally develop intercultural knowledge and awareness. The third course included an embedded study-away experience, but was not designed to develop intercultural knowledge and awareness. Using the IDI, data was collected from a total of 24 students: 21 women and three men. Twelve students were in the classroom only, without an embedded study-away experience, while the other 12 did have an embedded study-away experience.

\section{IDI}

Researchers, instructors, and others administering the instrument to participants must attend a two-day qualifying seminar before being allowed to purchase, administer, and analyze the resulting data. The IDI is composed of a 50-item inventory in which participants are asked to rate the level of their agreement with a series of statements about their relationship to and evaluation of cultural difference on a five-point ( 1 to 5 range) Likert-type scale. Examples of such statements include: People from other cultures are dishonest compared to people from my own culture; all people are basically the same. Unfortunately, due to a written agreement with the developers of the IDI, the instrument cannot be copied or provided in an appendix.

Different sets of statements assess participants' orientation toward denial, polarization (defense and reversal measured as separate scales), minimization, acceptance, and adaptation. Within a developmental model like the DMIS, increased intercultural knowledge and sensitivity means see forward movement through the stages of the model toward an intercultural mindset, which is reflected in higher scores on the IDI. As a theory-based instrument, the IDI meets the standard scientific criteria for a valid and reliable psychometric instrument (Hammer et al., 2003).

\section{Findings}

The findings in Table 1 show the pre IDI scores for the students who completed the classroom only (A) averaged at 76.80 with an average post IDI score of 83.48 . This results in an $8 \%$ change in the mean score. This finding supports hypothesis 1 by measuring a significant change in intercultural development. The pre IDI scores for the students who completed the classroom and an embedded experience (B) without emphasis on intercultural development, averaged at 93.38 with an average post IDI score of 93.43 resulted in a negligible change in the score $(<0.05 \%)$. This finding does not support hypothesis 2 , since change in intercultural development was very small. The pre IDI scores for the students who completed the classroom and the 
embedded experience (C) with emphasis on intercultural development averaged at 112.00 with an average post IDI score of 122.32 . This results in an $8 \%$ change in the score. This finding supports hypothesis 3 by measuring a significant change in intercultural development.

With scores on the IDI ranging from 55 to 145 , a score of 100 represents the mean or average. A score below 85 indicates that a person is primarily operating in the realm of polarization; 85 to 114.99 represents a primary orientation in minimization, and score of 115 to 129.99 indicates acceptance while scores higher than 130 indicate adaptation. Although on average students under condition (A) did not move out of the stage of polarization, these results nevertheless suggest development in students' intercultural sensitivity with scores moving closer to the realm of minimization. Students under condition (B) did not move much at all and remained in minimization, while students under condition (C) moved, on average, from high minimization into the realm of acceptance. As described above, movement into the acceptance stage represents a fundamental shift in worldview. In this stage, people are beginning to understand that their own culture is one of many equally complex ways of organizing human behavior. They are tolerant and are comfortable knowing that there is no "right" answer, that beliefs and practices need to be evaluated within a given cultural context. It appears that the combination of an emphasis on intercultural development with an embedded study-away experience can have promising results.

Table 1

Comparison of Pre-post IDI Developmental Scores

\begin{tabular}{lccc}
\hline Students' Experience & Number of students & Group Pre/Post Scores & Change \\
\hline $\begin{array}{l}\text { Classroom, with intentional intercultural } \\
\text { development (no embedded experience) }\end{array}$ & 12 & $76.80 / 83.48$ & $8.0 \%$ \\
\hline $\begin{array}{l}\text { Classroom, without an intentional intercultural } \\
\text { development with an embedded experience }\end{array}$ & 6 & $93.38 / 93.43$ & $0.0 \%$ \\
\hline $\begin{array}{l}\text { Classroom, with intentional intercultural } \\
\text { development and an embedded experience }\end{array}$ & 6 & $112.00 / 122.32$ & $8.44 \%$ \\
\hline
\end{tabular}

\section{Conclusions}

The purpose of this research was to consider the value of an embedded intercultural experience. Is it critical to the development of intercultural knowledge and awareness? This study examined whether a week long embedded study-away experience can increase intercultural knowledge and awareness (with and without an emphasis on intercultural development) and whether students who participated in an intercultural course only can experience an increase in intercultural knowledge and awareness. The change in intercultural knowledge and awareness was determined by comparing the pre and post individual profile score of each participant. The average changes in the group scores under three conditions are provided.

Supporting hypothesis 1, the study confirmed prior research results that an intentional focus on the development of intercultural knowledge and awareness has a significant impact on intercultural development. Overall, the mean score for the 12 students who participated under condition A increased from 76.80 to 83.48 (with a maximum possible score of 145) on the IDI instrument measuring intercultural sensitivity. This increased occurred without a study-away experience.

Hypothesis 2, which predicted an increase in pre- to post-IDI scores, when students experience an embedded study-away experience only, was not supported. Although the six students who participated in the study-abroad experience had a significantly higher pre-travel score (93.38 versus 76.80 for students with both 
study away and intentional intercultural development), the change scores for the study-abroad only students were flat, with scores for these students rising 0 points, showing no change.

The results under condition $\mathrm{C}$, movement from the high minimization stage (112.00) to the acceptance stage (122.32) are greater than those found by Rexeisen and Al-Khatib (2009), in which students who studied abroad had a pre-travel IDI score of 93.45 and a post-travel score of 103.48 and whose students' average score started (116.86) and ended (119.82) in the minimization stage (Anderson \& Lawton, 2011). This movement into the acceptance stage suggests the students' exposure to people from another culture helped them not only to recognize and appreciate cultural differences in behavior and values, but also to understand that their own culture is one of many equally complex ways of organizing human behavior. In the acceptance stage, people are tolerant and are comfortable knowing that there is no "right" answer, that beliefs and practices need to be evaluated within a given cultural context. People in this stage accept the viability of different ways of thinking and behaving (Bennett, 1993), that represents a fundamental shift in worldview. Overall, students who were exposed to both an embedded study-away experience and an intentional focus on intercultural development had the greatest gains. However, it should be noted that several of these students were in their fourth year of study, while students under condition A were all first year with limited college coursework. However, these students experienced equivalent change in their scores. Further research is needed to determine why these differences occurred.

\section{Limitations}

An important limitation to this study is the number of participants $(n=24)$ and, in particular, the very small sub-group of students $(n=6)$ under conditions B and C. Clearly, the small sample size limits the ability to extrapolate these findings to a larger group. If a larger group could be recruited for a future study, this would not only strengthen the analysis, it could offer the possibility of comparing scores under all three conditions. However, this study did include a control group of students who did not study abroad (condition A), but who had similar coursework as students under condition C. This approach can help discern changes due to study aboard versus coursework only, as recommended by Williams (2005), Rust et al. (2013), and Sample (2013).

\section{Implications}

Despite these limitations, this study does offer additional evidence of the importance of intercultural knowledge and sensitivity-building knowledge in conjunction with an intercultural study-abroad experience. Though this pilot study is very small, with just 24 participants, this research model can be duplicated, so educators can develop courses for those students who, for a variety of reasons, cannot participate in a study-away experience.

In conclusion, regardless of how intercultural knowledge is developed, it is clearly critical to a students' success as future global leaders. Cassiday (2005) found that effective leaders were the ones who demonstrated intercultural competence. Students will be at a disadvantage in today's global marketplace, if they fail to develop intercultural cognitive, affective, and behavioral skills (Deardorff, 2009).

\section{References}

Anderson, P. H., \& Lawton, L. (2011). Intercultural development: Study abroad vs. On-campus study. Frontiers: The Interdisciplinary Journal of Study Abroad, 21, 86-108. 
Anderson, P. H., Lawton, L., Rexeisen, R. J., \& Hubbard, A. C. (2006). Short-term study abroad and intercultural sensitivity: A pilot study. International Journal of Intercultural Relations, 30(4), 457-469.

Bennett, M. J. (1986). A developmental approach to training for intercultural sensitivity. International Journal of Intercultural Relations, 10(2), 179-196.

Bennett, M. J. (1993). Towards ethnorelativism: A developmental model of intercultural sensitivity. In R. M. Paige (Ed.), Education for the intercultural experience (pp. 21-71). Yarmouth: Intercultural Press.

Cassiday, P. A. (2005). Expatriate leadership: An organizational resource for collaboration. International Journal of Intercultural Relations, 29(3), 391-408.

Deardorff, D. K. (2009). Implementing intercultural competence assessment. In D. K. Deardorff (Ed.), The SAGE handbook of intercultural competence (pp. 477-491). Los Angeles: SAGE Publications.

Hammer, M. R. (2009). The intercultural development inventory: An approach for assessing and building intercultural competence. In M. A. Moodian (Ed.), Contemporary leadership and intercultural competence: Exploring the cross-cultural dynamics within organizations (pp. 203-108). Thousand Oaks: Sage.

Hammer, M. R. (2011). Additional cross-cultural validity testing of the intercultural development inventory. International Journal of Intercultural Relations, 35, 474-487.

Hammer, M. R., \& Bennett, M. J. (2001). The intercultural development inventory (IDI) manual (Qualifying Seminar, Portland, Oregon).

Hammer, M. R., Bennett, M. J., \& Wiseman, R. (2003). Measuring intercultural sensitivity: The intercultural development inventory. International Journal of Intercultural Relations, 27, 421-443.

Jackson, J. (2009). Intercultural learning on short-term sojourns. Intercultural Education, 20(1-2), 59-71.

Paige, R. M., Cohen, A. D., \& Shively, R. L. (2004). Assessing the impact of a strategies-based curriculum on language and culture learning abroad. Frontiers: The Interdisciplinary Journal of Study Abroad, 10, 253-276.

Pederson, P. J. (2009). Teaching towards an ethnorelative worldview through psychology study abroad. Intercultural Education, 20(1-2), 73-86.

Rexeisen, R., \& Al-Khatib, J. (2009). Assurance of learning and study abroad: A case study. Journal of Teaching in International Business, 20(3), 192-207.

Rust, K. G., \& Morris, C. E. (2013). Intercultural competency development in conjunction with a short term study away experience: Changes in undergraduate students. China-USA Business Review, 12(8), 796-803.

Rust, K. G., Forster, B., Niziolek, A., \& Morris, C. E. (2013). Study abroad and intercultural coursework: Their effects on change in intercultural competence. International Research and Review, 3(1), 3-13.

Sample, S. G. (2013). Developing intercultural learners through the international curriculum. Journal of Studies in International Education, 17(5), 554-572.

Soria, K. M., \& Troisi, J. (2014). Internationalization at home alternatives to study abroad: Implications for students' development of global, international, and intercultural competencies. Journal of Studies in International Education, 18, 261-280.

Vande Berg, M. (2009). Intervening in student learning abroad: A research-based inquiry. Intercultural Education, 20(1-2), 15-27.

Williams, T. R. (2005). Exploring the impact of study abroad on students' intercultural communication skills: Adaptability and sensitivity. Journal of Studies in International Education, 9(4), 356-371. 